\title{
Paediatric Contacts to a Danish Emergency Medical Dispatch Centre: What can we learn about paediatric emergencies?
}

Andersen K.1,2, Mikkelsen S. ${ }^{2,3}$, Jørgensen G.3,4 \& Zwisler S.T. 2,3,4

${ }^{1}$ Department of Clinical Research, University of Southern Denmark, Denmark

2 Department of Anaesthesiology \& Intensive Care, Odense University Hospital, Denmark

${ }^{3}$ Mobile Emergency Care Unit, Department of Anaesthesiology \& Intensive Care, Odense University Hospital, Denmark

${ }^{4}$ Emergency Medical Dispatch Centre, Region of Southern Denmark, Denmark

\section{BACKGROUND}

Little is known about paediatric emergency calls to Danish Emergency Medical Dispatch Centres. This study aimed to collect epidemiological and emergency response data regarding these calls.

\section{METHOD}

In this retrospective, descriptive study, we extracted data from the dispatch centre in the region of Southern Denmark. We examined audio recordings of all emergency calls made in February 2016 to identify calls concerning children (age $\leq 15$ years). We established how the incidents leading to these calls were classified by the dispatch centre staff, and which pre-hospital responses were dispatched. If multiple calls were made regarding the same emergency we included only the primary call.

\section{RESULTS}

The dispatch centre received 7.052 calls in February 2016. Four hundred and eighty-five $(7.0 \%)$ concerned children. We excluded 19 repeated calls and analysed the remaining 466 . The median age was four years (range $0-15$ ). The incidents leading to the calls were most frequently classified as "convulsions" (22.1\%) (fig. 1). The most common emergency response was immediate dispatch of an ambulance with sirens and lights (level A) with emergency physician support (56.4\%) (table 1 ).

\section{CONCLUSION}

One call in fourteen concerned children. The children were typically classified as being critically ill, often with convulsions, and assigned level A-responses. The dispatch centre commonly dispatched emergency physicians to assist the ambulances.

\section{FIGURE 1: CLASSIFICATION OF INCIDENTS LEADING TO THE EMERGENCY CALLS}

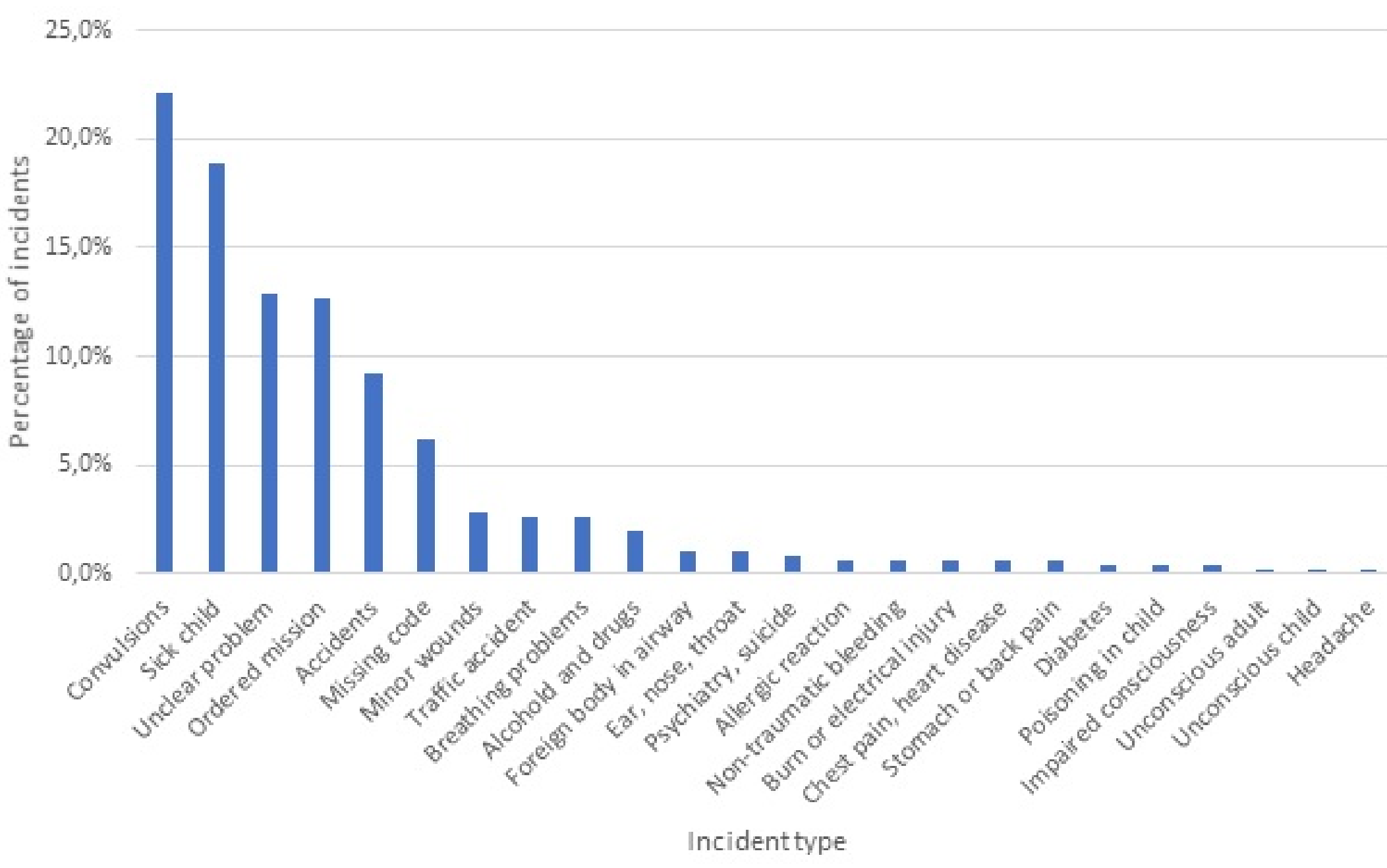

\section{TABLE 1: ASSIGNED} PRE-HOSPITAL RESPONSES

Emergency response

n (\%)

Level A with emergency physician 263 (56.4)

Level A

$64(13.7)$

Level B

64 (13.7)

Level E

59 (12.7)

Level A with paramedic

$15(3.2)$

Level C

$1(0.2)$

All

$466(100)$

\section{CONTACT}

Kasper Andsersen

Mail: kaand12@student.sdu.dk

\section{TAKE HOME MESSAGES}

> Paediatric calls accounted for $7 \%$ of all contacts.

> The calls commonly concerned convulsions.

> The calls were mostly assigned high-level pre-hospital responses. 